\title{
Cannabis for pain: a cross-sectional survey of the patient information quality on the Internet
}

\author{
Jeremy Y. Ng ${ }^{*}$ D, Darragh A. Dzisiak(D) and Jessica B. Saini
}

\begin{abstract}
Background: Cannabis has increasingly become an alternative treatment for chronic pain, however, there is evidence of concomitant negative health effects with its long-term usage. Patients contemplating cannabis use for pain relief commonly see information online but may not be able to identify trustworthy and accurate sources, therefore, it is imperative that healthcare practitioners play a role in assisting them in discerning the quality of information. The present study assesses the quality of web-based consumer health information available at the intersection of cannabis and pain.
\end{abstract}

Methods: A cross-sectional quality assessment of website information was conducted. Three countries were searched on Google: Canada, the Netherlands, and the USA. The first 3 pages of generated websites were used in each of the 9 searches. Eligible websites contained cannabis consumer health information for pain treatment. Only English-language websites were included. Encyclopedias (i.e. Wikipedia), forums, academic journals, general news websites, major e-commerce websites, websites not publicly available, books, and video platforms were excluded. Information presented on eligible websites were assessed using the DISCERN instrument. The DISCERN instrument consists of three sections, the first focusing on the reliability of the publication, the second investigating individual aspects of the publication, and the third providing an overall averaged score.

Results: Of 270 websites identified across searches, 216 were duplicates, and 18 were excluded based on eligibility criteria, resulting in 36 eligible websites. The average summed DISCERN score was 48.85 out of 75.00 (SD = 8.13), and the average overall score (question 16) was 3.10 out of 5.00 (SD =0.62). These overall scores were calculated from combining the scores for questions 1 through 15 in the DISCERN instrument for each website. Websites selling cannabis products/services scored the lowest, while health portals scored the highest.

Conclusion: These findings indicate that online cannabis consumer health information for the treatment/ management of pain presents biases to readers. These biases included websites: (1) selectively citing studies that supported the benefits associated with cannabis use, while neglecting to mention those discussing its risks, and (2) promoting cannabis as "natural" with the implication that this equated to "safe". Healthcare providers should be involved in the guidance of patients' seeking and use of online information on this topic.

Keywords: Cannabis, Marijuana, Pain, Quality of Information, Consumer Health Information, Internet

\footnotetext{
*Correspondence: ngjy2@mcmaster.ca

Department of Health Research Methods, Evidence, and Impact, Faculty of Health Sciences, McMaster University, Michael G. DeGroote Centre for Learning and Discovery, Room 2112, 1280 Main Street West, Hamilton, Ontario L8S 4K1, Canada
}

(c) The Author(s). 2021 Open Access This article is licensed under a Creative Commons Attribution 4.0 International License, which permits use, sharing, adaptation, distribution and reproduction in any medium or format, as long as you give appropriate credit to the original author(s) and the source, provide a link to the Creative Commons licence, and indicate if changes were made. The images or other third party material in this article are included in the article's Creative Commons licence, unless indicated otherwise in a credit line to the material. If material is not included in the article's Creative Commons licence and your intended use is not permitted by statutory regulation or exceeds the permitted use, you will need to obtain permission directly from the copyright holder. To view a copy of this licence, visit http://creativecommons.org/licenses/by/4.0/. 


\section{Background}

Pain is categorized into a number of different types, including acute (occurs suddenly and is usually associated with an injury), chronic (pain lasting for longer than 6 months, even after an injury has healed), nociceptive (pain stemming from the stimulation of pain receptors, usually in response to inflammation), and neuropathic pain (resulting from a dysfunction of the nervous system) (Santos-Longhurst 2018). According to a 2015 report, $17.6 \%$ of American adults experience severe levels of pain, and in 2016 an estimated 20.6\% of Americans experience chronic pain (NIH analysis shows Americans are in pain 2018; Dahlhamer et al. 2018). Many of the individuals experiencing pain may consider or seek cannabis as a potential treatment option. While the long-term impacts of prolonged cannabis use remain understudied, there is preliminary evidence suggesting that negative health effects are concomitant with long-term usage, such as tuberculosis (with smoking cannabis), addiction (seen in $17 \%$ of heavy users who start using cannabis in adolescence), altered brain development, increased risk of schizophrenia, lowered IQ, and cyclic vomiting (Nugent et al. 2017; Schreiner and Dunn 2012; Volkow et al. 2014). Patients contemplating using cannabis for pain relief commonly seek information online but may not be able to identify trustworthy and accurate sources (Diviani et al. 2015). Therefore, it is important that healthcare providers are aware of the quality of such information commonly accessed by patients, in order that they are prepared to guide them in identifying trustworthy sources.

Few published studies have assessed the quality of online consumer health information specific to cannabis. One study examined the label accuracy of cannabidiol products sold online (Bonn-Miller et al. 2017), while others have evaluated the accuracy of cannabis claims found on popular websites (Sperry 2018), and information specific to cannabis addiction (Khazaal et al. 2008). Other studies have reviewed the quality of cannabis information published in magazines and newspapers (Halvorson et al. 2018; Montané et al. 2005). In general, the authors of these aforementioned studies concluded that the quality of cannabis information were often of very poor quality. Additionally, another study involved a qualitative analysis of online forum discussions on cannabis use and attention deficit hyperactivity disorder (ADHD) (Mitchell et al. 2016); the authors reported that the majority of information posted on these forums portrayed cannabis positively as a treatment option. They also found that online forum users believed that cannabis was encouraged by healthcare practitioners (Mitchell et al. 2016).

Approximately $4.5 \%$ of the internet searches worldwide are for health-related information, and a trend can be seen since 2004 that shows a steady increase in cannabis-related Google searches. In fact, from 2004 to 2016, cannabis-related searches have increased by $75 \%$ on Google.com (Morahan-Martin 2003; Lubin 2016). Despite this aforementioned published literature, to our knowledge, no research has assessed the quality of such information at the specific intersection of cannabis and pain, with the exception of a recently published study investigating the quality of online patient resources about cannabidiol for relief of hip or knee arthritis (Premkumar et al. 2021). Our study, however, is broader and applies to any type of pain in general. Given that a high prevalence of Americans experience severe pain (17.6\%, among other pain types) it is important to evaluate the quality consumer health information available on this topic (NIH analysis shows Americans are in pain 2018). Therefore, the purpose of the present study is to assess the quality of cannabis consumer health information for the treatment/ management of pain.

\section{Methods}

\section{Search strategy and screening}

A search strategy was developed to yield websites commonly visited by patients seeking information about cannabis for pain. Google was the only search engine used, as it holds $90 \%+$ of the market share allowing us to replicate "typical" patient information-seeking behavior (Search Engine Market Share Worldwide 2020). Search terms were developed by JYN and included the following: "cannabis for pain", "marijuana for pain", and "weed for pain." For each of the search terms, websites found on the first 3 Google search pages were considered for eligibility. We justified this decision based on the fact that past research has found that the first search page contains $92 \%$ of website traffic, with a $95 \%$ decrease for the second page, a $78 \%$ decrease for the third page, and subsequent decreases for each following page of results (Chitika Insights The value of Google result positioning 2013). Thus, searching beyond the third page would likely not reflect typical patient information-seeking behavior. DAD conducted the searches on 4 May 2020 across three countries that have either partially legalized or decriminalized cannabis as follows: Canada (Google.ca), the Netherlands (Google.nl), and the USA (Google.com). We searched Google across these three different countries, allowing our findings to be more generalizable and internationally representative, with respect to commonly visited websites. We specifically chose to search these three countries based on the fact that the use of medical cannabis has been legalized for approximately a decade in Canada, the Netherlands, and a number of states within the USA, allowing for the accumulation of a greater quantity of cannabis health-related information to exist online (University of Georgia 2020; Tattrie 2016; Centre For 
Public Impact (CPI) 2016). Searches were conducted using the Google Chrome browser in incognito mode to ensure that the websites retrieved were not influenced by previous browser search histories.

\section{Selection of quality assessment instrument}

The DISCERN instrument is a questionnaire designed to assess the quality of written consumer health information. We selected the DISCERN instrument for the present study, as it has been found to be a valid and reliable tool for assessing the quality of publications (i.e., flyers, websites) about treatment choices. The DISCERN instrument consists of 16 questions, divided into three sections as follows: reliability of information (8 questions), specific details of information about treatment choices (7 questions), and an overall quality rating (1 question). Each item is rated based on a 5-point Likert scale, ranging from no/does not fulfill criterion (1 point) to yes/fulfills criterion (5 points) (DISCERN 2020; Charnock et al. 1999). It should be noted, however, that DISCERN cannot assess the validity of the written information, but rather the reliability of the information source (i.e., the DISCERN instrument cannot be used to judge the scientific accuracy of a publication's sources).

\section{Eligibility criteria}

DAD and JBS reviewed the search results from the first 20 websites on the first 3 Google webpages that were included for each search term, and duplicate websites across searches were removed. Websites were screened for eligibility and included if they contained at least one webpage that contained cannabis consumer health information for the treatment/management of pain. For the purpose of this study, we identified and included cannabis based on the definition provided by the World Health Organization: https://www.who.int/substance abuse/facts/cannabis/en/. The following website types were excluded: general news websites (i.e., websites reporting on a wide range of topics and with no focus on cannabis or pain-specific information), peer-reviewed journals/articles, encyclopedia (i.e. Wikipedia) entries, non-English language websites, forums (i.e., Reddit), ebooks, major e-commerce websites (i.e., Amazon), video platforms (i.e., YouTube), websites targeted towards healthcare professionals rather than consumers, websites that were not publicly available, and websites that focused on cannabis as an addiction instead of as a treatment. While it is acknowledged that many of these websites may contain consumer health information (i.e., forums and videos), these were excluded because, as previously mentioned, the DISCERN instrument is designed for assessing written publications.

\section{Data extraction and website quality assessment}

DAD and JBS data extracted the following items: website URL, website type, types of cannabis therapies, types of non-cannabis therapies (if present), whether the website appeared in more than one search (different search terms and/or regions), as well as scores for the sixteen DISCERN questions. For the purpose of this study, different webpages from the same website captured by searches were considered a single item for the purpose of DISCERN instrument quality assessment; we therefore conducted a quality assessment of websites and not individual webpages.

Following the identification of all eligible websites and to standardize the data extraction and the use of the DISCERN instrument, JYN, DAD, and JBS pilot tested its use on three separate websites and resolved any discrepancies across each item through discussion. The pilot test allowed for the standardization of how each DISCERN question is applied. Next, DAD and JBS independently completed the data extraction and assessed the quality of consumer health information on each eligible website using the DISCERN instrument. JYN then reviewed all scores with DAD and JBS to resolved any discrepancies that arose. The average of the two assessors' scores was calculated for each question across all websites, providing an overall summed DISCERN score between 15 and 75 , based on the scores for the first 15 questions. Additionally, the average scores and standard deviations for each DISCERN item was also calculated along with an average score for all 16 items.

\section{Results}

\section{Search results}

A total of 270 webpages were identified across searches, and after removing 199 duplicate webpages, 71 unique webpages remained. Twenty-eight webpages did not meet our exclusion criteria, for the following reasons: general news website $(n=8)$, peer-reviewed journal/article $(\mathrm{n}=8)$, targeted towards healthcare professionals rather than consumers $(n=5)$, not publicly available $(n=$ $2)$, online forums $(n=2)$, major e-commerce website $(n$ $=1)$, discussed cannabis as an addiction not a treatment $(n=1)$, and invalid URL $(n=1)$. Of the remaining 43 webpages, 7 webpages belonged to websites already captured by the search and were collapsed into a single item. Therefore, 36 unique websites were deemed eligible for data extraction, and were assessed using the DISCERN instrument. This process is depicted in Fig. 1.

\section{General characteristics of eligible websites}

Eligible websites were identified as belonging to 1 of 6 categories, as follows: health portal (websites that provide information on many types of diseases/conditions, $n=8$ ), professional (websites marketing cannabis as a medical 


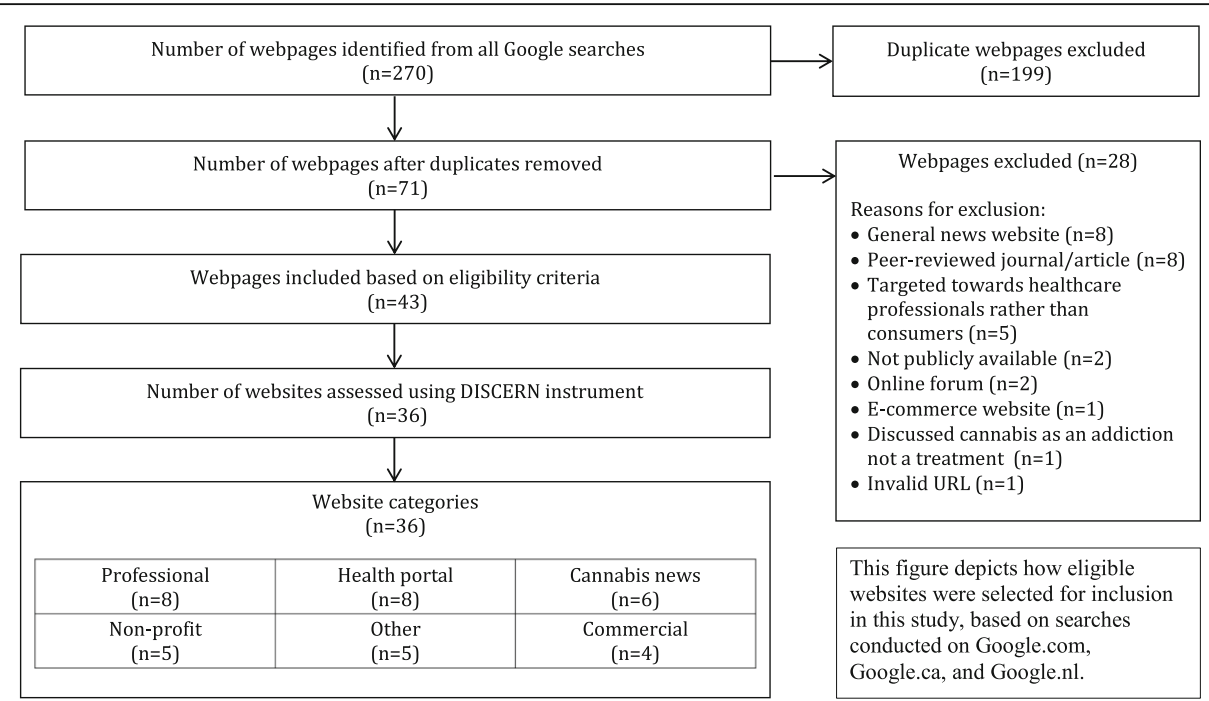

Fig. 1 Web information search strategy and assessment flowchart

therapy, $n=8$ ), cannabis news (websites that report specifically on emerging cannabis and pain related information, $n=6$ ), non-profit (organization websites operating in a research and/or educational capacity, $n=5$ ), commercial (websites that market cannabis products/services, $n=4$ ), and finally, other (websites that do not fit into any of the aforementioned categories, $n=5$ ). Of the 36 eligible websites, 28 appeared in multiple searches, while 8 appeared only once (3 websites from USA, 3 websites from the Netherlands, and 2 websites from Canada). Of the 36 websites, the following non-cannabis topics were discussed: surgery $(n=28)$, pharmaceutical medications $(n=28)$, and complementary and alternative medicine (CAM, $n=$ 23). Full details associated with the general characteristics of eligible websites are shown in Table 1.

\section{DISCERN instrument ratings}

The mean summed DISCERN score was 48.85 (SD = 8.13, range from 33.50 to 65.00). The mean overall score (question 16) was 3.10 ( $\mathrm{SD}=0.62$, range from 2.00 to 4.50). The three highest scoring websites were Medical News Today (65.00), WebMD (64.50), and Very Well Health (62.50). The lowest scoring websites were SepaPain (37.50), People's Cali (37.50), and Denver Dispensaries (33.50). DISCERN scores for each eligible website are provided in Table 2.

\section{Trends identified across resources assessed}

\section{Questions 1-8: reliability of the publication}

Question 1 asks if the aims of the publication are clear. Specifically, this question ascertains what the publication is about, what it is meant to cover, and who might find it useful. In general, health portals scored highest in this section, with commercial websites scoring the lowest.
The mean score for this question was $3.89(\mathrm{SD}=0.89)$, and the scores ranged from 1 to 5 .

Question 2 seeks to understand if the publication has achieved its aims (the aims that were evaluated by question 1). This question is closely linked to question 1 . In general, websites that scored low on question 1 also scored poorly on question 2 . Health portals scored highest on this section, and commercial sites scored lowest, however, question 2 also saw lower scores for professional sites, compared to question 1 . The mean score for this question was 3.96 (SD = 0.94), and the scores ranged from 1.5 to 5 .

Question 3 asks if the information in the publication is relevant. This question ascertains whether the publication addresses the questions that readers might ask. It also asks whether recommendations and suggestions within the publication concerning treatment choices are realistic or appropriate. Professional and commercial websites generally scored most poorly on this section. The mean score for this question was 3.38 ( $\mathrm{SD}=0.78$ ), and the scores ranged from 2 to 4.5

Question 4 asks whether the sources used to compile the information available in the publication are clear and accessible. Cannabis news, commercial, and professional websites generally scored very poorly on this section (the lowest scoring website was SepaPain, with a score of 1). The mean score for this question was 3.19 (SD = $0.98)$, and the scores ranged from 1 to 5 .

Question 5 evaluates whether the dates of any source information and all publication revisions are readily available on the site. Generally health portals scored well on this question while commercial websites scored poorly. The mean score for this question was 2.97 (SD = 1.24), and the scores ranged from 1 to 5 . 


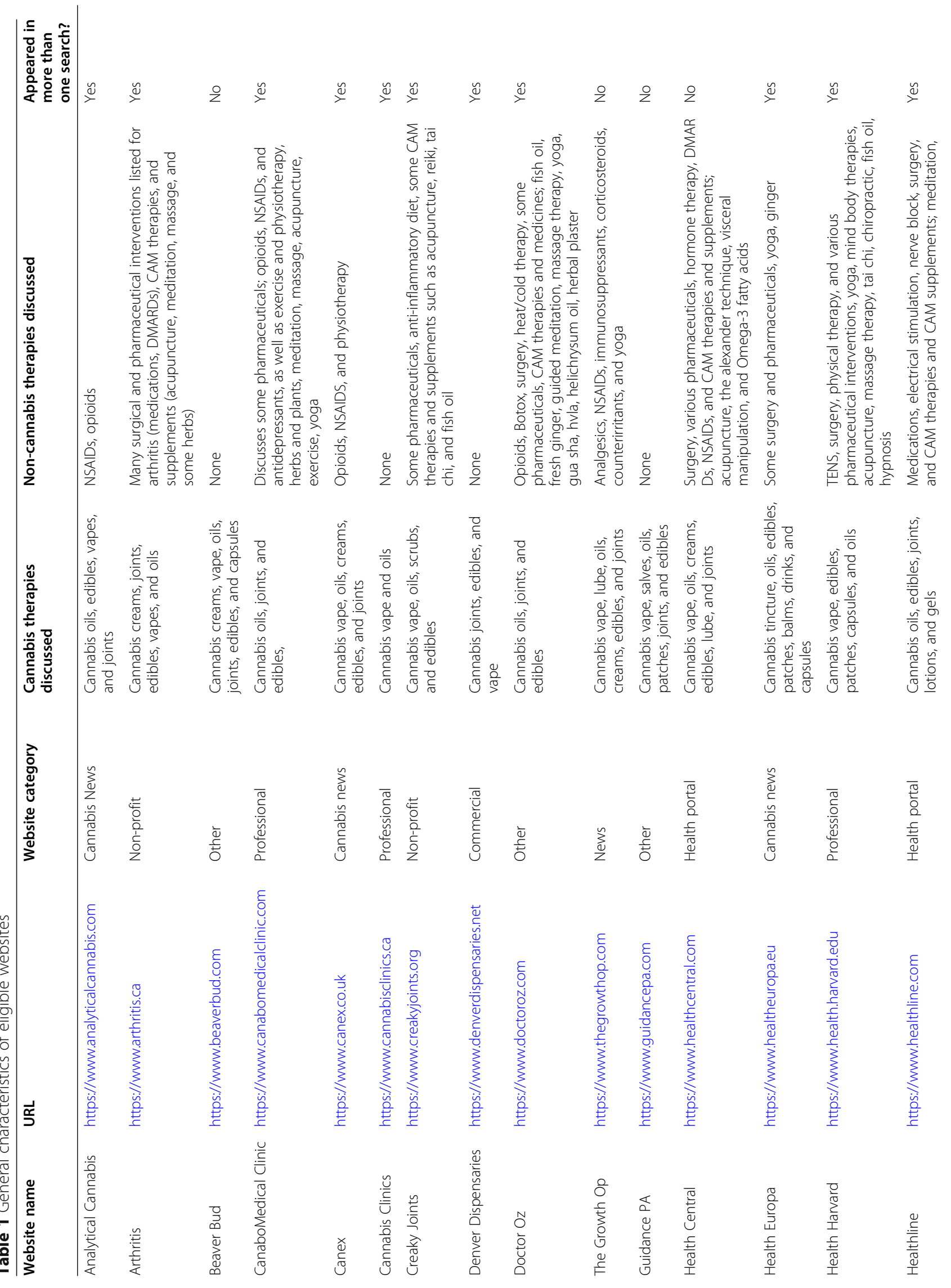




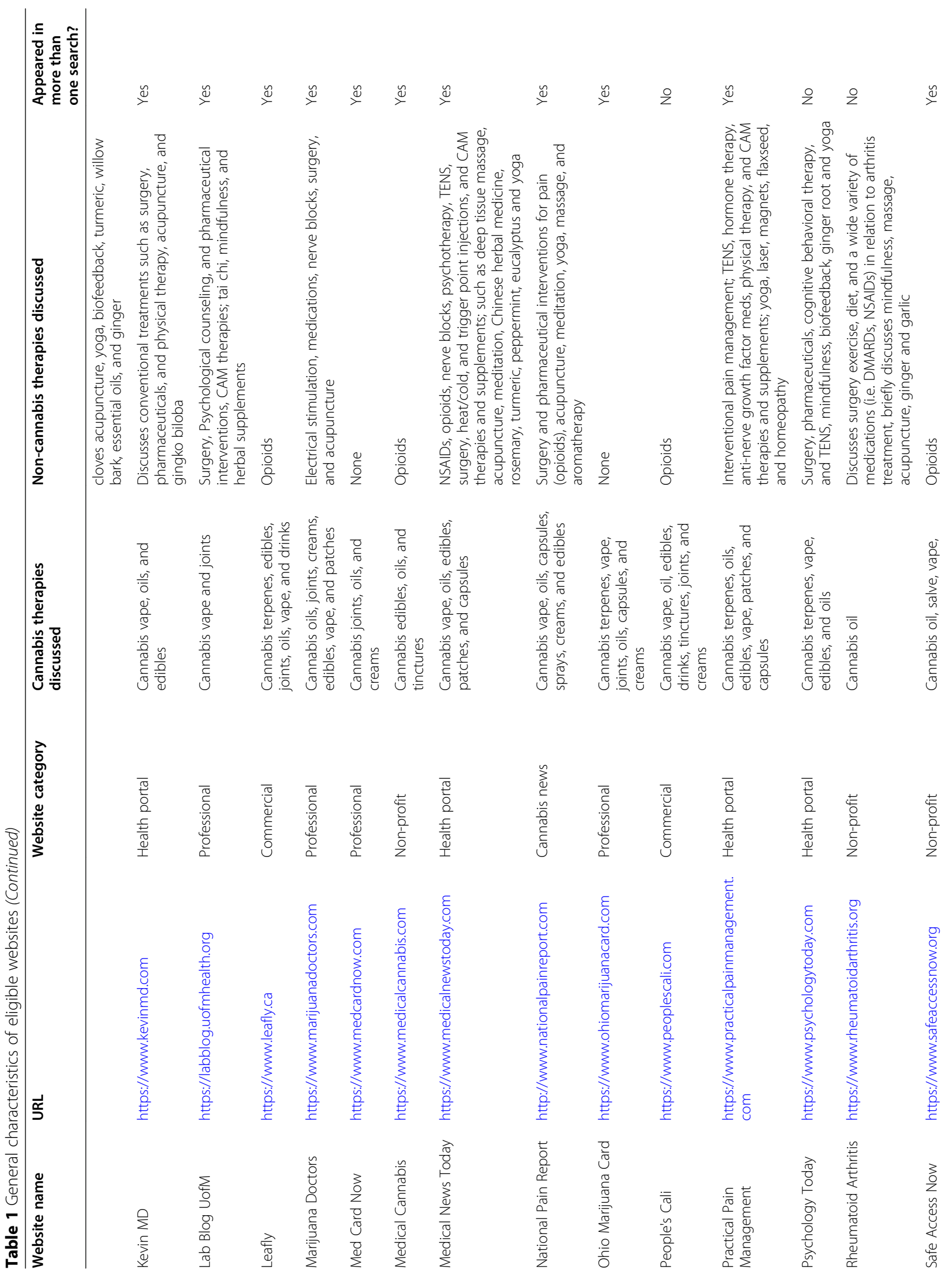




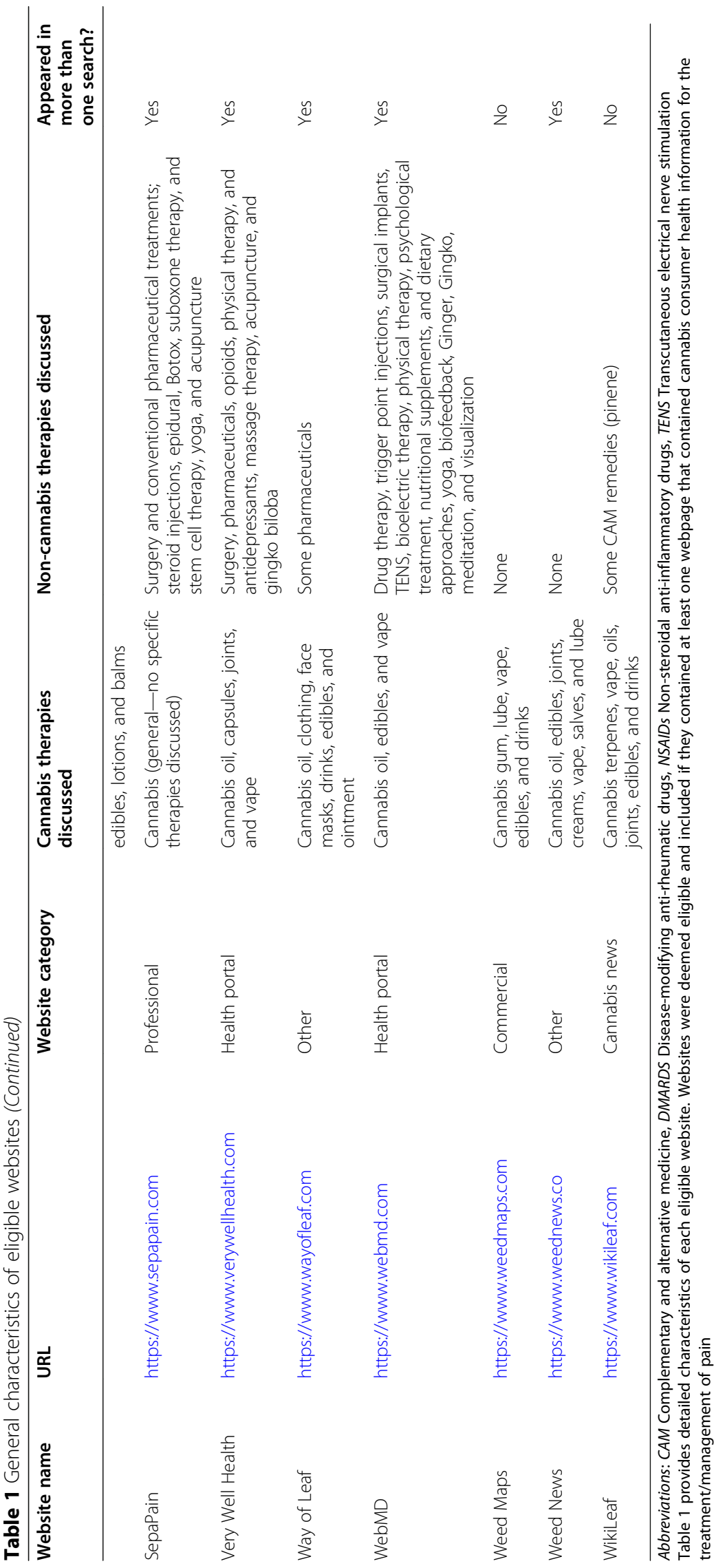




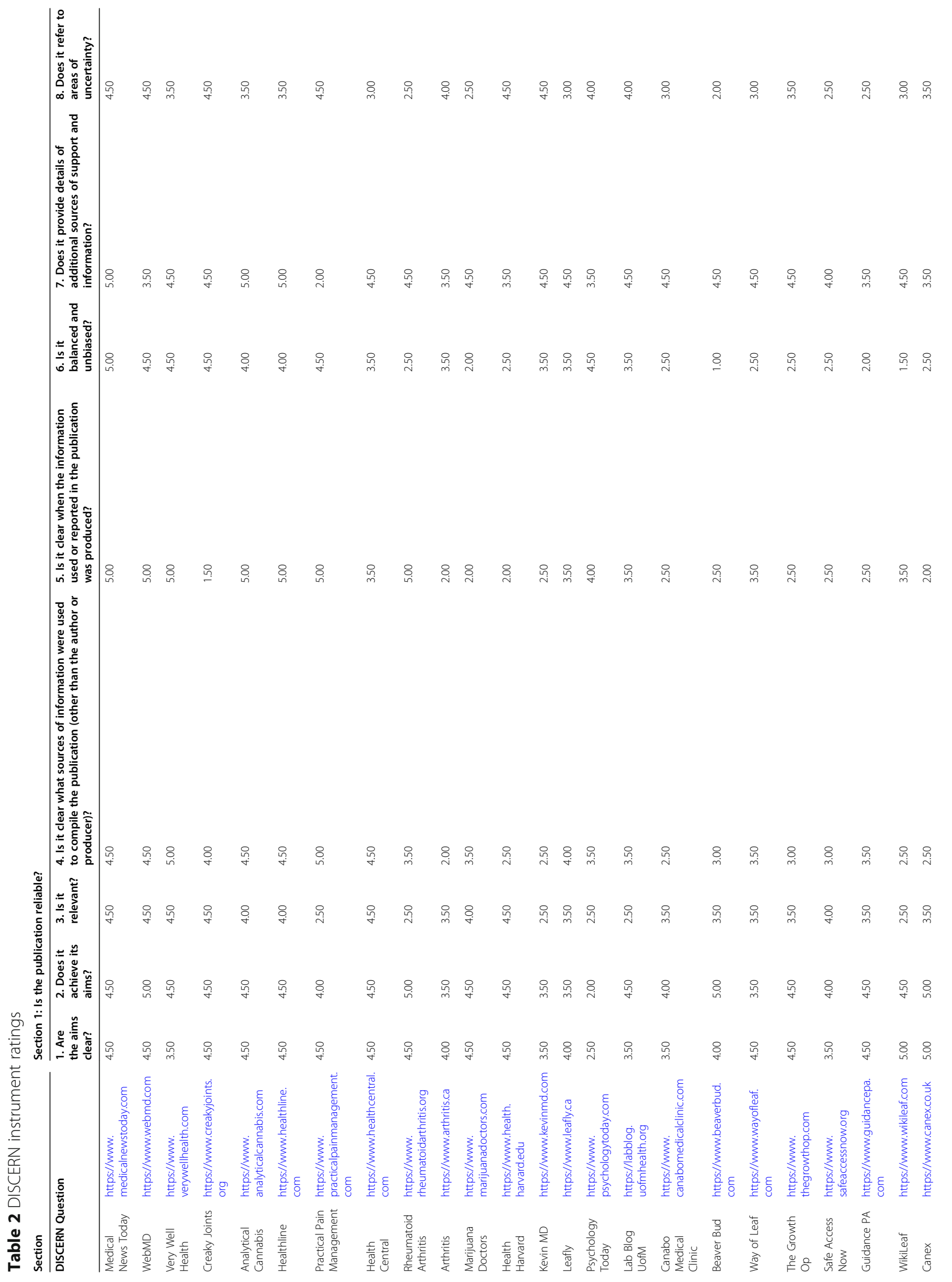




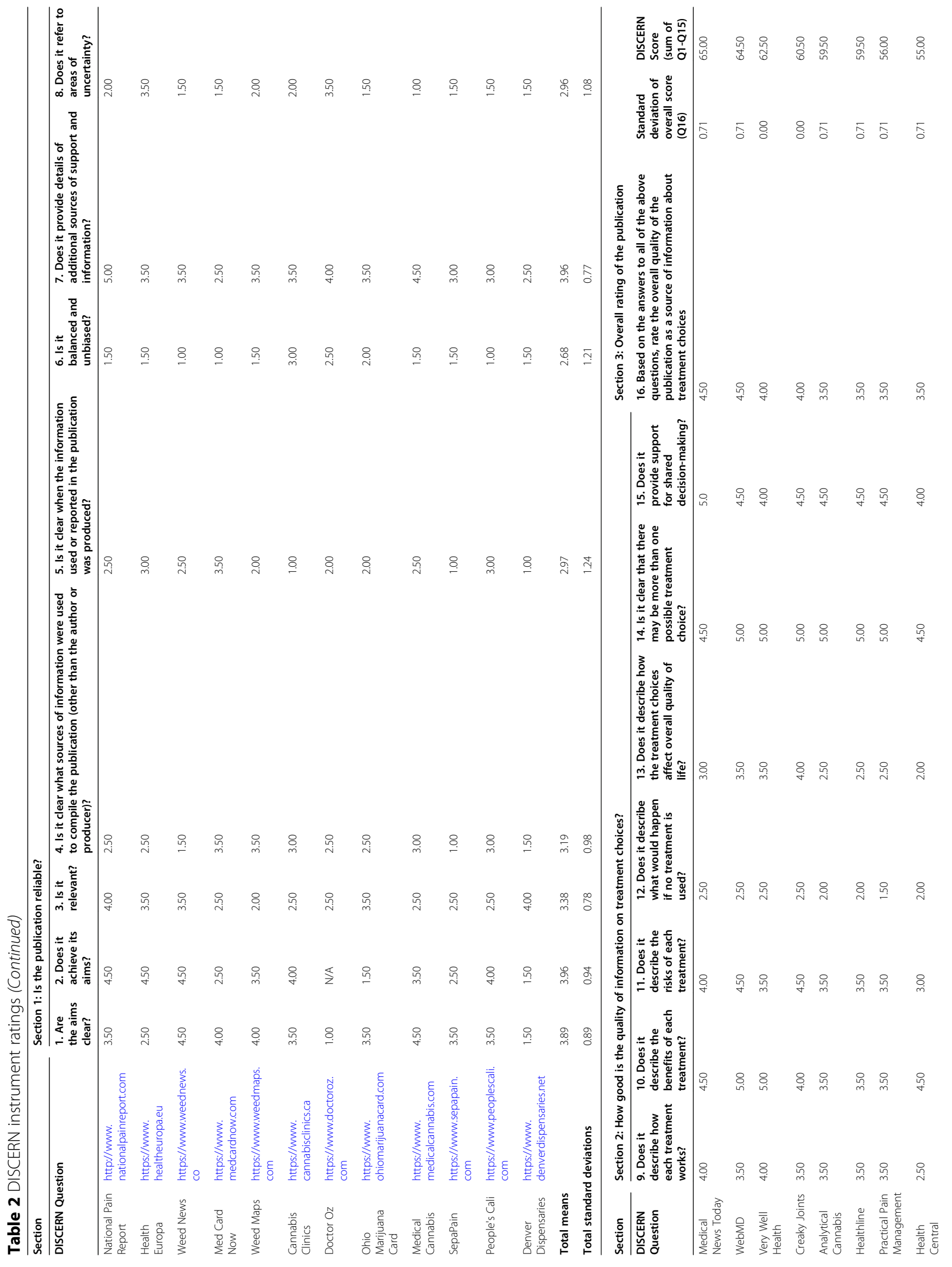




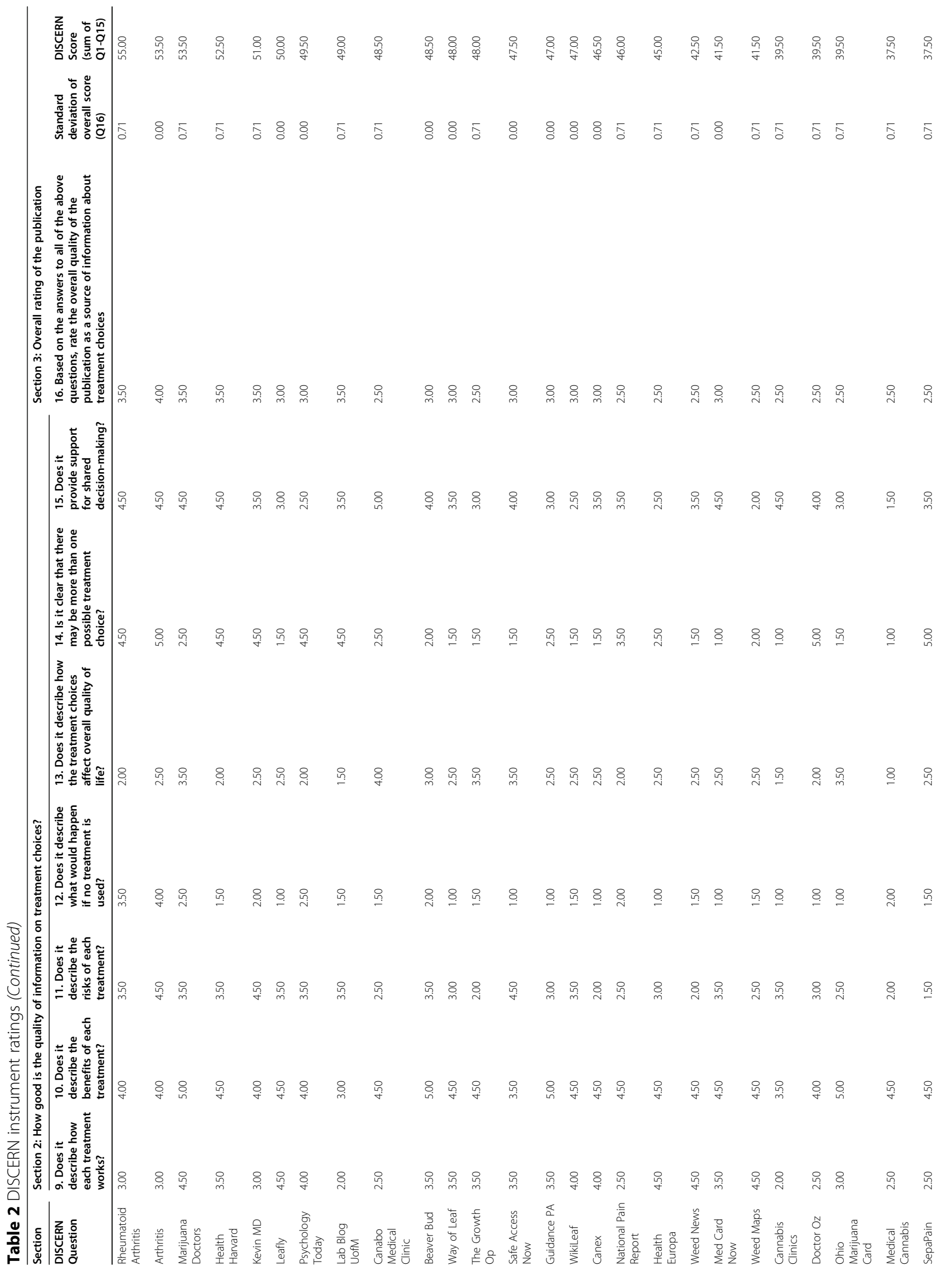




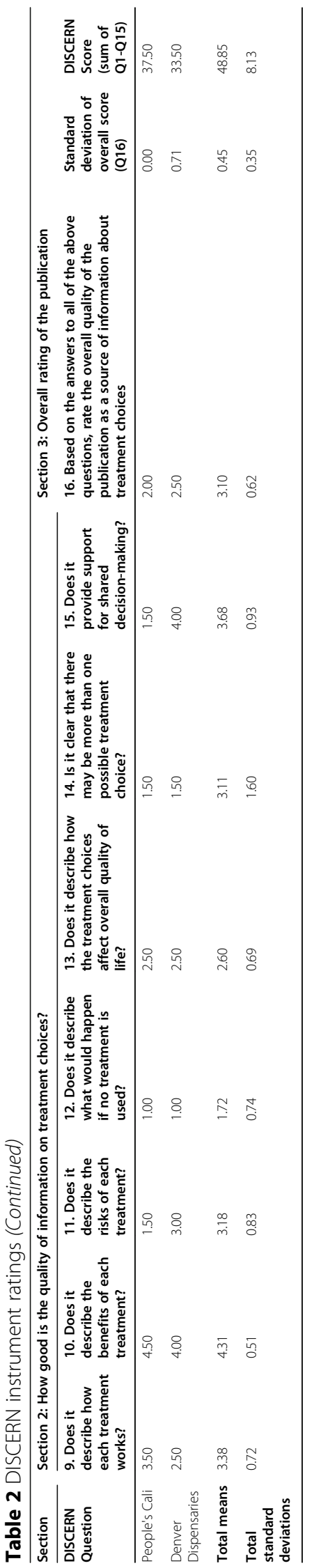


Question 6 asks if the source of consumer health information is balanced and unbiased. Both professional and commercial websites (and cannabis news websites to a lesser degree) scored lower in this category when compared to health portals and non-profit websites. Eleven out of 12 professional and commercial websites scored below a 3 on this item. These websites presented more persuasive and positive language when discussing cannabis, had fewer reputable or easily traceable sources, and discussed the possibility of alternatives to cannabis much less frequently as opposed to health portal or nonprofit websites. The mean score for this question was $2.68(\mathrm{SD}=1.21)$, and the scores ranged from 1 to 5 .

Most websites scored comparatively higher on question 7 of the DISCERN instrument. In fact, only 4 out of 36 websites scored below a 3.5 for this question. This section asks if information presented on the website was supported by additional sources, and whether links to pages/websites with similar topic information were available within webpages. Most websites provided references and hyperlinks to other websites (such as government agencies or other pages within the website with similar topics). The mean score for this question was 3.96 (SD = 0.77 ), and the scores ranged from 2 to 5 .

Question 8 asks if the publication refers to areas of uncertainty. For example, this question ascertains if there is discussion of the gaps in knowledge or differences in expert opinion concerning treatment choices. Commercial and professional websites generally scored very poorly on this section (i.e., Denver Dispensaries and Med Card Now). However, the lowest scoring website for this particular question was Medical Cannabis, a non-profit website. The mean score for this question was 2.96 (SD $=1.08$ ), and the scores ranged from 1 to 4.5 .

\section{Questions 9-15: specific details of the information about treatment choices}

Question 9 assesses whether the publication describes how the proposed treatment works. Commercial and professional websites, in general, scored most poorly on this section, as they provided little to no explanation of treatment mechanisms. Such websites typically only provided a list of treatment benefits, while providing, at most, a cursory explanation of the treatment's physiological mechanisms. The lowest two scoring websites were Lab Blog UofM and Cannabis Clinics (both professional websites). The mean score for this question was $3.38(\mathrm{SD}=0.72)$, and the scores ranged from 2 to 4.5 .

Question 10 asks if the publication describes the benefits of each treatment. Most websites scored well on this question, with detailed descriptions of the many possible benefits associated with cannabis use included. Of the 36 included websites, 23 scored at or above a 4.5 on question 10, and only one website, Lab Blog UofM, scored below a 3.5. The mean score for this question was 4.31 $(\mathrm{SD}=0.51)$, and the scores ranged from 3 to 5 .

Question 11 investigates if the publication accurately and fully describes the risks of each proposed treatment. Most websites, with the exception of health portals and non-profits, scored poorly on this question. Most commercial, cannabis news, and professional websites either only discussed treatment risks briefly, or omitted mention of risks completely. The two lowest scoring websites were People's Cali (commercial) and SepaPain (professional) with a score of 1.5 each, indicating an almost complete lack of risk warnings. The mean score for this section was $3.18(\mathrm{SD}=0.83)$, and the scores ranged from 1.5 to 4.5 .

Question 12 of the DISCERN instrument assesses whether a publication explains what would happen to a patient who did not undergo treatment. Twenty-eight websites scored a 2 or lower, with only one website scoring above a 3.5. While a variety of treatment options were often discussed with respect to pain conditions, the impact of receiving no treatment for these conditions was rarely discussed. Although some websites stated that the pain condition could be resolved without treatment, they did not directly discuss how chronic conditions could progress without treatment, or provide more details about this information. Some websites, even if briefly, supported the idea that cannabis is a preferential pain management option to opioids, claiming that it causes less damage and cannot result in addiction. The mean score for this question was $1.72(\mathrm{SD}=0.74)$, and the scores ranged from 1 to 4 .

Question 13 asks if the website takes into account the various impacts a specific treatment choice could have on an individual's quality of life (i.e., financial strain, ability to continue work, and any potential impact on interpersonal relationships). Only two websites in this category scored higher than a 3.5, indicating an overall lack of this information. Twenty-two websites discussed this generally in terms of short-term effects of cannabis (i.e., decreased driving ability), but did not discuss longterm impacts on patients' quality of life, while the remaining 14 websites did not discuss this at all. The mean score for this question was $2.60(\mathrm{SD}=0.69)$, and the scores ranged from 1 to 4 .

Question 14 assesses whether it is made clear in the publication that there may be more than one possible treatment choice. In general, professional and commercial websites did not mention any possible alternatives to cannabis therapy for pain, and solely focused on describing cannabis benefits. In contrast, health portals scored higher for this question. The mean score for this question was $3.11(\mathrm{SD}=1.60)$, and the scores ranged from 1 to 5 .

Finally, question 15 asks if the publication provides support for shared decision-making. In other words, this 
question asks if the publication encourages patients to discuss treatment options with a healthcare provider, such as a physician, prior to using medical cannabis. Generally, cannabis news and commercial websites scored poorly on this section. The mean score for this question was 3.68 ( $\mathrm{SD}=0.93$ ), and the scores ranged from 1.5 to 5 .

\section{Recommended websites for patients and consumers}

The five highest-rated websites had a mean summed score of 61.20 (out of 75), and a mean overall score (question 16) of 4.20 out of 5 . All 5 websites were either characterized as a health portal or a non-profit. All of these websites scored highly on question 15 , as they placed a significance on shared decision-making (i.e., discussing treatment options with friends, family, and healthcare providers). In addition, question 6 of the DISCERN instrument asks whether the publication is balanced and unbiased, and all 5 websites scored 3.5 or higher on this question as they provided more objective language, while accounting for any potential competing interests. All 5 websites aimed to provide less biased information and encouraged the reader to discuss treatment options with their family and professionals. Additional characteristics of the 5 recommended websites are provided in Table 3.

\section{Discussion}

The purpose of this study was to assess the quality of online cannabis consumer health information for the treatment/management of pain. We identified 36 eligible websites that contained cannabis consumer health information for pain. The mean summed DISCERN score was $48.85(\mathrm{SD}=8.13$, range from 33.50 to 65.00$)$. The mean overall score (question 16) was $3.10(\mathrm{SD}=0.62$, range from 2.00 to 4.50 ). In general, health portal and non-profit websites comprised the top $40 \%$ of the overall DISCERN ratings (question 16), while the remaining $60 \%$ consisted of news, professional, and commercial websites.

It is hoped that the present study's findings will aid healthcare professionals in their understanding of the quality of information surrounding the intersection of cannabis and pain available to patients and the general public online. Published research that has assessed the quality of online patient information in general has indicated that many commonly visited websites are maintained by individuals or organizations with direct financial interests in promoting health treatments or therapies (Kunst and Khan 2002). Often, the information provided on these websites have been found to be incomplete, anecdotal, or not representative of evidencebased research, and tended to over-exaggerate positive aspects and underplay (or completely omit) information surrounding risks and negative side effects (Macedo et al. 2020; Chen et al. 2018). Additionally, it has been found that $60 \%$ of internet users seeking medical information believed that what they obtained online was "the same" or "better" than the resources obtained from their physician (Diaz et al. 2002). Further to this, it has been found that while patients are largely able to discern biases in information provided on commercial websites, they often also reject high quality websites solely based on website design (Sillence et al. 2007). Another study also identified that source credibility had no significant effect on a consumer's evaluation of the quality of online information (Bates et al. 2006).

\section{Comparative literature}

It is reasonable to infer that patients who seek cannabis information online are not exempt from the behaviors found in the aforementioned studies, which may put them at risk of experiencing negative health outcomes. One study characterized the interest in using cannabis as a treatment for cancer online, and the propagation of this information on social media. The authors found that false news stories and advertisements on social media which claimed that cannabis can cure cancer garnered more online interactions than those debunking these claims (Shi et al. 2019). Furthermore, another study identified that many websites promote the view that cannabis use by pregnant women and children is entirely safe (Keyhani et al. 2018). Perhaps most worrying, another study also found that online cannabis misinformation is responsible for lowering the risk perceptions among adolescents, thereby potentially lowering their inhibitions, leading them to engage in use (Belenko et al. 2009). With respect to painspecific information, there have also been a few studies assessing the quality of online consumer health information in the context of complementary or alternative medicine, which is comprised of a diverse group of therapies of which cannabis is sometimes included. One study evaluated the quality of complementary or alternative medicine consumer health information for arthritis, and found that many websites lacked source transparency and risk reporting ( $\mathrm{Ng}$ et al. 2021a). Two other studies investigated the quality of complementary or alternative medicine consumer health information for low back pain and neck pain, respectively, and reported that many websites did not adequately report the risks or adverse sideeffects of treatment options adequately ( $\mathrm{Ng}$ and Gilotra 2020; Ng et al. 2021b). Similar findings have also been reported with respect to commonly used herbal products such as St. John's wort (Thakor et al. 2011), kratom ( $\mathrm{Ng}$ et al. 2021c), and ephedra ( $\mathrm{Ng}$ et al. 2021d). Another issue of concern includes the fact that 


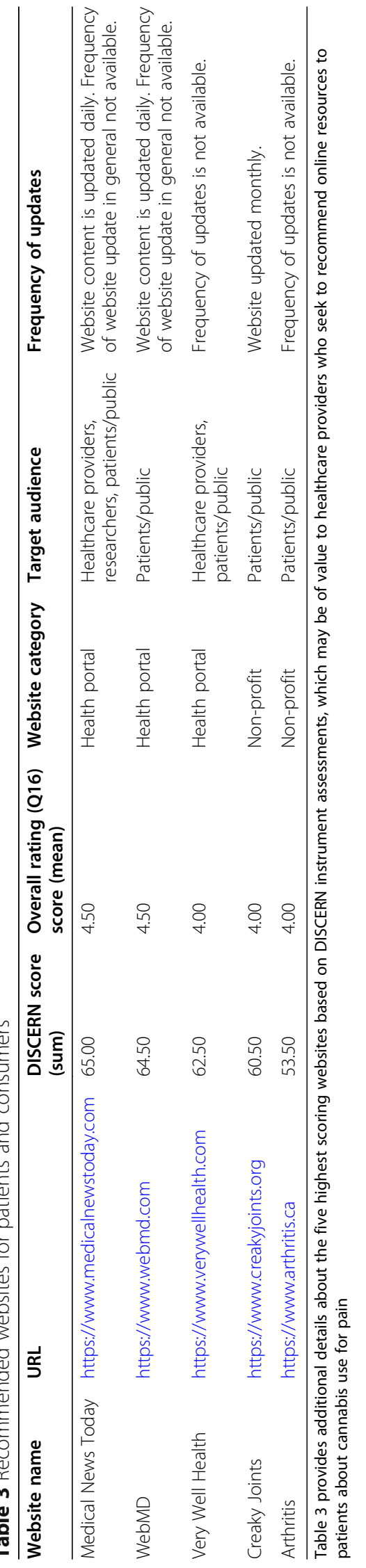


across numerous jurisdictions, even where medical cannabis is legalized, physicians report lacking knowledge and information, while acknowledging their need for greater and continuing education, on this topic (Kansagara et al. 2020; Philpot et al. 2019; Ziemianski et al. 2015; Ng et al. 2021e; Zolotov et al. 2018). Collectively, it is clear that cannabis misinformation is commonly found on the internet, and the present study's findings only reinforce the need for healthcare professionals to be actively aware of this information quality in order to better assist their patients in identifying trustworthy and accurate cannabis resources online.

\section{Strengths and limitations}

A notable strength of our study includes the use of the DISCERN instrument to assess the quality of our subset of websites, as it has been found to be both valid and reliable in assessing the quality of consumer health information. By interpreting the DISCERN instrument scores across websites, and using a series of search strategies that replicate typical patient behavior, it is likely that our findings are generally also applicable to other websites that discuss cannabis in the context of pain. This helps to provide insight into the type and depth of counseling which should be afforded to patients seeking information about cannabis for pain online. Furthermore, website screening, data extraction, and quality assessments were all performed independently and in duplicate. All three authors then met to discuss any discrepancies without unduly modifying original scores.

With respect to limitations, it should be acknowledged that all websites were assessed cross-sectionally. The internet is constantly changing, and the content on this subset of websites are likely no exception. An additional limitation includes the fact that only English-language websites were included and assessed, based on study resource limitations. We must also acknowledge that different search results may have appeared despite identical Google search strategies, if conducted in different regions' native languages (i.e., Dutch for Google.nl, Spanish for Google.com) or geographic locations (i.e., conducting the search in the Netherlands or the USA), despite searching using incognito mode on the Google Chrome browser. It may be of value to assess the quality of information provided on websites originating from other countries (i.e., Mexico (Secretaría de Gobernación 2017) or South Africa (South Africa Health Products Regulatory Authority 2017), which both decriminalized cannabis for medical use in 2017), especially as a global trend tends towards legalization across more jurisdictions around the world.

\section{Conclusion}

Given the fact that a high proportion of individuals suffer from pain globally, a large subset of this population undoubtedly seeks consumer health information online about cannabis. The purpose of this study was to assess the quality of online cannabis consumer health information for the treatment/management of pain. Our findings indicate that the consumer health information available at the intersection of cannabis and pain is commonly incomplete and biased. While health portal and non-profit websites generally provide higher-quality information, commercial, professional, and cannabis-focussed news websites tended to only present the positive aspects of cannabis while downplaying the potential risks of use. Our results also corroborates findings from a number of published studies which have reported that consumers may be at risk of making poor health-related decisions following information-seeking online, both in general and in the context of cannabis use. Healthcare providers need to be aware of the information their patients seek pertaining to cannabis online and should be prepared to guide them in identifying high-quality resources which promote the safe and effective use of this therapy.

\section{Acknowledgements}

JYN was awarded a Research Scholarship and an Entrance Scholarship from the Department of Health Research Methods, Evidence and Impact, Faculty of Health Sciences at McMaster University.

\section{Authors' contributions}

JYN conceptualized and designed the study, collected the data, interpreted and analyzed the data, drafted the manuscript, and gave final approval of the version to be published. DAD collected the data, interpreted and analyzed the data, provided contributions and critically revised the manuscript, and gave final approval of the version to be published. JBS collected the data, interpreted and analyzed the data, provided contributions and critically revised the manuscript, and gave final approval of the version to be published. All authors read and approved the final manuscript.

\section{Funding}

This study was unfunded.

\section{Availability of data and materials}

All relevant data are included in this manuscript.

\section{Declarations}

Ethics approval and consent to participate

This study involved a search and review of publicly available online information only; it did not require ethics approval or consent to participate.

Consent for publication

All authors gave consent to this manuscript's publication.

Competing interests

The authors declare that they have no competing interests.

Received: 9 October 2020 Accepted: 1 August 2021

Published online: 16 August 2021

\section{References}

Bates BR, Romina S, Ahmed R, Hopson D. The effect of source credibility on consumers' perceptions of the quality of health information on the Internet. Med Inform Internet Med. 2006;31(1):45-52. https://doi.org/10.1080/1463923 0600552601.

Belenko S, Dugosh KL, Lynch K, Mericle AA, Pich M, Forman RF. Online illegal drug use information: an exploratory analysis of drug-related website 
viewing by adolescents. J Health Commun. 2009;14(7):612-30. https://doi org/10.1080/10810730903089622.

Bonn-Miller MO, Loflin MJE, Thomas BF, Marcu JP, Hyke T, Vandrey R. Labeling accuracy of cannabidiol extracts sold online. Jama. 2017;318(17):1708-9. https://doi.org/10.1001/jama.2017.11909.

Centre For Public Impact (CPI). The Dutch policy on marijuana use - continuity and change. 2016 [cited $2021 \mathrm{Jul}$ 18]. Available from: https://www. centreforpublicimpact.org/case-study/dutch-policy-marijuana-use-continuitychange/

Charnock D, Shepperd S, Needham G, Gann R. DISCERN: an instrument for judging the quality of written consumer health information on treatment choices. J Epidemiol Community Health. 1999;53(2):105-11. https://doi.org/1 0.1136/jech.53.2.105.

Chen AT, Taylor-Swanson L, Buie RW, Park A, Conway M. Characterizing websites that provide information about complementary and integrative health: systematic search and evaluation of five domains. Interact J Med Res. 2018; 7(2). https://doi.org/10.2196/ijmr.9803.

Chitika Insights The value of Google result positioning. Chitika Info. 2013 [cited 2020 May 10]. Available from: https://www.benchmark.no/wp-content/uploa ds/2020/04/chitikainsights-valueofgoogleresultspositioning.pdf

Dahlhamer J, Lucas J, Zelaya C, Nahin R, Mackey S, De Bar L, et al. Prevalence of chronic pain and high-impact chronic pain among adults — United States, 2016. MMWR Morb Mortal Wkly Rep. 2018;67(36):1001-6. https://doi.org/10. 5585/mmwr.mm6736a2.

Diaz JA, Griffith RA, Ng JJ, Reinert SE, Friedmann PD, Moulton AW. Patients' use of the internet for medical information. J Gen Intern Med. 2002;17(3):180185. https://doi.org/10.1046/j.1525-1497.2002.10603.x

DISCERN. The DISCERN Instrument [Internet]. [cited 2020 Apr 14]. Available from: http://www.discern.org.uk/discern_instrument.php

Diviani N, Putte BVD, Giani S, Weert JCV. Low health literacy and evaluation of online health information: a systematic review of the literature. J Med Internet Res. 2015;17(5). https://doi.org/10.2196/jmir.4018.

Halvorson RT, Stewart CC, Thakur A, Glantz SA. Scientific quality of health-related articles in specialty cannabis and general newspapers in San Francisco. J Health Commun. 2018;23(12):993-8. https://doi.org/10.1080/10810730.2018.1 534906.

Kansagara D, Morasco BJ, lacocca MO, Bair MJ, Hooker ER, Becker WC. Clinician knowledge, attitudes, and practice regarding cannabis: results from a national Veterans Health Administration survey. Pain Med. 2020;21(11):31806. https://doi.org/10.1093/pm/pnz322.

Keyhani S, Steigerwald S, Ishida J, Vali M, Cerdá M, Hasin D, et al. Risks and benefits of marijuana use. Ann Intern Med. 2018;169(5):282-90. https://doi. org/10.7326/M18-0810.

Khazaal Y, Chatton A, Cochand S, Zullino D. Quality of web-based information on cannabis addiction. J Drug Addict Educ. 2008;38(2):97-107. https://doi.org/1 0.2190/DE.38.2.a.

Kunst H, Khan KS. Quality of web-based medical information on stable COPD: comparison of non-commercial and commercial websites. Health Info Libr J. 2002;19(1):42-8. https://doi.org/10.1046/j.0265-6647.2002.00366.x.

Lubin G. Americans are searching for weed more than ever, according to Google. Business Insider. 2016. Available from: https://www.businessinsider.com/a mericans-google-marijuana-2016-9

Macedo AC, de Faria AOV, Bizzi I, Moreira FA, Colasanti A, Ghezzi P. Online information on medical cannabis may rise unrealistic expectations and downplay potential side effects. arXiv.org. 2020. Available from: https://arxiv. org/abs/2004.02330

Mitchell JT, Sweitzer MM, Tunno AM, Kollins SH, Mcclernon FJ. "I use weed for my ADHD": a qualitative analysis of online forum discussions on cannabis use and ADHD. Plos One. 2016;11(5). https://doi.org/10.1371/journal.pone.01 56614.

Montané E, Duran M, Capellà D, Figueras A. Scientific drug information in newspapers: sensationalism and low quality. The example of therapeutic use of cannabinoids. Eur J Clin Pharmacol. 2005;61(5-6):475-7. https://doi.org/10.1 007/s00228-005-0916-7.

Morahan-Martin J. How Internet users find, evaluate, and use online health information. Cyberpsychol Behav. 2003;7(5):497-510. https://doi.org/10.1089/ cpb.2004.7.497.

$\mathrm{Ng} J$ Y, Ans M, Marwaha A. Assessing the quality of information provided on websites selling Kratom (Mitragyna speciosa) to consumers in Canada. Subst Abuse Treat Prev Policy. 2021c;16(1):1-5. https://doi.org/10.1186/s13011-02100361-2.
Ng JY, Gilotra K. Web-information surrounding complementary and alternative medicine for low back pain: a cross-sectional survey and quality assessment. Integr Med Res. 2020:100692. https://doi.org/10.1016/ j.imr.2020.100692.

Ng JY, Gilotra K, Usman S, Chang Y, Busse JW. Attitudes toward medical cannabis among family physicians practising in Ontario, Canada: a qualitative research study. CMAJ Open. 2021e;9(2):E342-8. https://doi.org/10.9778/ cmajo.20200187

Ng JY, Marwaha A, Ans M. The quality of information available about Ephedra sinica on online vendor websites: the Canadian consumer experience. Complement Ther Med. 2021d;57:102674. https://doi.org/10.1016/j.ctim.2 021.102674.

$\mathrm{Ng} J$ Y, Saini JB, Dzisiak DA. Evaluating the quality of websites providing complementary and alternative medicine patient information for neck pain. Adv Integr Med. 2021b. https://doi.org/10.1016/j.aimed.2021.05.001.

$\mathrm{Ng} J$ Y, Vacca A, Jain $\mathrm{T}$. The quality of online consumer health information at the intersection of complementary and alternative medicine and arthritis. Adv Rheumatol. 2021a;61(1). https://doi.org/10.1186/s42358021-00162-y.

$\mathrm{NIH}$ analysis shows Americans are in pain. National Institutes of Health. U.S. Department of Health and Human Services; 2018 [cited 2021 Jul 21]. Available from: https://www.nih.gov/news-events/news-releases/nih-analysisshows-americans-are-pain

Nugent SM, Morasco BJ, O'neil ME, Freeman M, Low A, Kondo K, et al. The effects of cannabis among adults with chronic pain and an overview of general harms. Ann Intern Med. 2017;167(5):319-31. https://doi.org/10.7326/M170155.

Philpot LM, Ebbert JO, Hurt RT. A survey of the attitudes, beliefs and knowledge about medical cannabis among primary care providers. BMC Family Pract. 2019;20(1):1-7. https://doi.org/10.1186/s12875-019-0906-y.

Premkumar A, Almeida BA, Lopez J, Pean CA, Nwachukwu BU, Sculco PK. The quality of online resources available to patients regarding cannabidiol for symptomatic relief of hip or knee arthritis is poor. J Am Acad Orthop Surg Glob Res Rev. 2021;5(1). https://doi.org/10.5435/JAAOSGlobal-D-20-00241.

Santos-Longhurst A. Types of pain: how to recognize and talk about them. Healthline. 2018 [cited 2021 Jul 21]. Available from: https://www.healthline. com/health/types-of-pain

Schreiner AM, Dunn ME. Residual effects of cannabis use on neurocognitive performance after prolonged abstinence: a meta-analysis. Exp Clin Psychopharmaco. 2012;20(5):420-9. https://doi.org/10.1037/a0029117.

Search Engine Market Share Worldwide. StatCounter Global Stats. [cited 2020 Aug 11]. Available from: https://gs.statcounter.com/search-engine-market-sha re/all

Secretaría de Gobernación. DECRETO por el que se reforman y adicionan diversas disposiciones de la Ley General de Salud y del Código Penal Federal. 2017 [cited 2021 Jul 21]. Available from: http://www.dof.gob.mx/nota_detalle. php?codigo $=5487335 \&$ fecha $=19 / 06 / 2017$

Shi S, Brant AR, Sabolch A, Pollom E. False news of a cannabis cancer cure. Cureus. 2019. https://doi.org/10.7759/cureus.3918.

Sillence E, Briggs P, Harris PR, Fishwick L. How do patients evaluate and make use of online health information? Social Science \&amp. Medicine. 2007;64(9): 1853-62. https://doi.org/10.1016/j.socscimed.2007.01.012.

South Africa Health Products Regulatory Authority. Cultivation of cannabis and manufacture of cannabis-related pharmaceutical products for medicinal and research purposes. 2017 [cited 2021 Jul 21]. Available from: https://sahpra. org.za/wp-content/uploads/2020/01/93b0b4262.44_Cannabiscultivation_v2_ Nov2019.pdf

Sperry ML. Accuracy of medical marijuana claims made by popular websites. J Pharm Pract. 2018;33(4):457-64. https://doi.org/10.1177/0897190018818907.

Tattrie J. Cannabis legalization in Canada. Can Encyclopedia. 2016; [cited 2021 Jul 18]. Available from: https://www.thecanadianencyclopedia.ca/en/article/ma rijuana-legalization-in-canada.

Thakor V, Leach MJ, Gillham D, Esterman A. The quality of information on websites selling St. John's wort. Complementary therapies in medicine. 2011; 19(3):155-160. 10.1016/j.ctim.2011.05.005

University of Georgia. Survey of marijuana law in the United States: history of marijuana regulation in the United States. LibGuides. 2020 [cited 2021 Jul 18]. Available from: https://ibguides.law.uga.edu/c.php?g=522835\&p=3575350

Volkow ND, Baler RD, Compton WM, Weiss SRB. Adverse health effects of marijuana use. N Engl J Med. 2014;370(23):2219-2227. https://doi.org/https:// doi.org/10.1056/NEJMra1402309, DOI: https://doi.org/10.1056/NEJMra1402309 
Ziemianski D, Capler R, Tekanoff R, Lacasse A, Luconi F, Ware MA. Cannabis in medicine: a national educational needs assessment among Canadian physicians. BMC Med Educ. 2015;15(1):1-7. https://doi.org/10.1186/s12909-01 5-0335-0.

Zolotov Y, Vulfsons S, Zarhin D, Sznitman S. Medical cannabis: an oxymoron? Physicians' perceptions of medical cannabis. International Journal of Drug Policy. 2018;57:4-10. https://doi.org/10.1016/j.drugpo.2018.03.025.

\section{Publisher's Note}

Springer Nature remains neutral with regard to jurisdictional claims in published maps and institutional affiliations.

Ready to submit your research? Choose BMC and benefit from:

- fast, convenient online submission

- thorough peer review by experienced researchers in your field

- rapid publication on acceptance

- support for research data, including large and complex data types

- gold Open Access which fosters wider collaboration and increased citations

- maximum visibility for your research: over $100 \mathrm{M}$ website views per year

At $\mathrm{BMC}$, research is always in progress. 